\title{
A study on patterns of needle - stick injuries among gynaecologic and general surgeons in open surgery
}

\author{
Abhinav Chadha ${ }^{1}$, Ashok Verma ${ }^{2 *}$, Sapna ${ }^{1}$ \\ ${ }^{1}$ Department of Obstetrics and Gynecology, Pt. Jawahar Lal Nehru Government Medical College Chamba, Himachal \\ Pradesh, India \\ ${ }^{2}$ Department of Obstetrics and Gynecology, Rajendra Prasad Government Medical College Kangra at Tanda, Himachal \\ Pradesh
}

Received: 06 October 2019

Accepted: 12 November 2019

\section{*Correspondence:}

Dr. Ashok Verma,

E-mail: dr.ashok_verma@yahoo.com

Copyright: ( ) the author(s), publisher and licensee Medip Academy. This is an open-access article distributed under the terms of the Creative Commons Attribution Non-Commercial License, which permits unrestricted non-commercial use, distribution, and reproduction in any medium, provided the original work is properly cited.

\section{ABSTRACT}

Background: An estimated 3,84,000 percutaneous injuries are reported by HCW in hospitals in the United States each year, placing them at risk of exposure to HIV, HBV, or HCV. Suture needles have been identified as the most frequent cause of injury. They are involved in as many as $44 \%$ of such injuries. This study is designed to note the NSI in major gynaecological procedures and surgical procedures using conventional method (CM) versus (VS) use of HK. Methods: Study was conducted over a period of 12 months from January 2017 to December 2017. 60 patients were included in this study and were divided into 2 groups A and B with 30 patients in each group. Group A was major surgery performed by conventional method; Group B was major surgery performed by using harmonic knife. NSI in two groups were studied and analyzed.

Results: Most of the operated patients were between 41-50 years age group. 16.6\% procedures were emergency and $83.3 \%$ were elective. NSI in conventional surgery was $63.3 \%$ in the surgeon and $33.3 \%$ with harmonic knife. There were $13.3 \%$ NSI in first assistant in conventional surgery and $23.3 \%$ in harmonic scalpel group. No such injuries were reported by second assistant in either group. Injuries were more in non-dominant hand in either groups in the surgeon and first assistant.

Conclusions: It is concluded that NSI are common in surgeons and first assistant. Such injuries are more in nondominant hand and in procedures where there is little exposure like vaginal hysterectomy. Use of innovative technologies like harmonic scalpel may be useful.

Keywords: Dominant hand, Disease transmission, Harmonic scalpel, Non scalpel injury, Open surgery, Surgery assistants

\section{INTRODUCTION}

A needle stick injury (NSI) can be a devastating event and are common among health care workers (HCW). NSI can result in substantial health consequences and psychological stress for HCW and their loved ones. ${ }^{1}$ NSI may introduce infective blood and body fluids (BBF) into the body of HCW, by a hollow bore needle, suturing needle, lancets, scalpels, and contaminated broken glass. ${ }^{2}$ Transmission of infection may depend upon amount of BBF involved, duration of exposure, depth of penetration, type of needle used, host factors and the amount of viruses in $\mathrm{BBF}^{3}$ The risks of viral transmission have been estimated to be $12-27 \%$ for hepatitis B virus (HBV), 
$0.5-18 \%$ for hepatitis $\mathrm{C}$ virus (HCV) and $0.3-0.4 \%$ for HIV ${ }^{4,5}$ Preventing NSI is the best approach against these diseases and it is an important part of exposure to any BBP prevention programme at the workplace. The rate of glove perforation has been investigated in various surgical specialties it is $10 \%$ for open lung surgery, 12 $24 \%$ for caesarean section, $28 \%$ for major gynecological surgery. ${ }^{6,7}$

An estimated 3,84,000 percutaneous injuries are reported by HCW in hospitals in the United States each year, placing them at risk of exposure to $\mathrm{HIV}, \mathrm{HBV}$, or $\mathrm{HCV}^{8}$

Suture needles have been identified as the most frequent cause of injury. They are involved in as many as $44 \%$ of such injuries. Scalpel blades are the second most frequent cause of injury, followed by syringes. ${ }^{9}$

The ultrasonically activated scalpel referred to by various names including harmonic knife (HK), harmonic scalpel (HS) and ultrasonic dissector or ultracision, was introduced into clinical use nearly a decade ago. The HK was originally devised as an instrument which could incise tissues while concomitantly achieving haemostasis. ${ }^{10}$ Conization of cervix using HK causes negligible bleeding. ${ }^{11}$ Rapid motion of the HK $(55,500$ cycles /sec), disrupts hydrogen bonds in the tissues and denatures proteins to form a coagulum, which seals off blood vessels. ${ }^{12}$ Since then it has proven to be an effective, efficient, and safe instrument for dissection and haemostasis in both open and laparoscopic surgical procedures.

The HK is useful for blunt dissections, since the tip is relatively cold due to minimal heat production and there is no danger of delivering current to the tissues, even accidentally. The splash of blood while grasping tissue can also be minimized. ${ }^{13}$

As most of NSIs occur during hand-to-hand passing of sharp instruments, suture needles, and other sharp devices, which may be avoided by using HK. ${ }^{9}$

NSI are mainly encountered during and after an intravenous line insertion, during various operative procedures, while recapping needles, inappropriate disposal, while transferring a body fluid between containers and syringes. ${ }^{13}$ Surgeons in training have the greatest risk of exposure to $\mathrm{BBP}$ due to increased propensity for injury while learning new technical skill sets. $^{14}$

There is no vaccine to prevent HIV infection or no definitive cure to treat AIDS. Hence, prevention is the best method to contain HIV infection. Preventing NSI is the best approach during surgical procedures. NSI may occur inadvertently hence prevention of NSI is extremely important to prevent the exposure of HIV from patients to doctors. Those who become infected are at risk of being uncompensated and deprived of gainful employment. ${ }^{15}$
Unless specific infective incidents can be identified, neither employer nor insurance company is likely to be generous.

Thus, this study is designed to note the NSI in major gynaecological procedures and surgical procedures using conventional method (CM) versus (VS) use of HK. Aim and objective of the study was:

- To study the needle stick injury sustained during major gynaecological and surgical operative procedure.

- To compare the incidence of needle stick injury sustained during major gynaecological and surgical operative procedure using conventional method versus use of harmonic knife.

\section{METHODS}

The study was conducted in the Department of Obstetrics and Gynaecology in conjunction with the department of General Surgery at Himalayan Institute of Medical Sciences (HIMS), Swami Ram Nagar, Dehradun, over a period of twelve months. Subjects were recruited after taking informed consent.

\section{Study design}

This was observational study. Study was conducted over a period of 12 months from January 2017 to December 2017. 60 patients were included in this study and were divided into 2 groups A and B with 30 patients in each group.

\section{Selection of subjects}

\section{Subjects were divided into two groups:}

- Group A: Surgery performed by conventional method for major gynaecological and surgical procedures.

- Group B: Surgery performed by using harmonic knife for major gynaecological and surgical procedures.

\section{Inclusion criteria}

- All patients who had undergone major elective and emergency gynaecological operations

- All patients who had undergone major elective and emergency surgical operations.

\section{Exclusion criteria}

- Patients, doctors and nurses who were unwilling to be included in this study

- Confirmed cases of HIV/Hepatitis B/ Hepatitis C infection. 
- All patients who had undergone laparoscopic operations

- All patients who had undergone obstetrical operations.

\section{Study tools}

- Structured study instruments (case reporting form) were used to record all cases to generate data.

- Johnson and Johnson company Cincinnati OH45422839 USA Harmonic knife.

\section{Study protocol}

- Detailed history, clinical examination, investigations (as applicable) and operative procedure were recorded in the performa.

- Surgeons and other members of surgical team were questioned at the end of the operative procedure for the incidence and site of needle stick injury.

\section{Data management and statistical analysis}

- Interpretation and analysis of result was carried out and differences in mean age, in two groups were tested by independent Student's t-test categorical.

Data were compared using Pearson Chi-square test or Fisher's exact test as appropriate. All analyses were conducted using SPSS version 17.

\section{RESULTS}

Age distribution of the subjects in the two groups is shown in Table 1. A total of 60 patients were included and were equally divided into 2 groups of 30 each. Highest number of subjects was in 41-50 years age group.

Table 1: Age distribution of source subjects $(n=60)$.

\begin{tabular}{|llll|}
\hline $\begin{array}{l}\text { Age } \\
\text { group } \\
\text { (years) }\end{array}$ & $\begin{array}{l}\text { No. of } \\
\text { operations }\end{array}$ & $\begin{array}{l}\text { Conventional } \\
\text { Method }\end{array}$ & $\begin{array}{l}\text { Harmonic } \\
\text { Knife }\end{array}$ \\
\hline$\leq 20$ & 2 & $\mathbf{N}=30$ & $\mathbf{N}=30$ \\
No. $(\%)$ & No. $(\%)$ \\
\hline $21-30$ & 6 & 2 & 0 \\
\hline $31-40$ & 11 & 3 & 3 \\
\hline $41-50$ & 22 & 5 & 6 \\
\hline $51-60$ & 10 & 10 & 12 \\
\hline$>60$ & 9 & 5 & 5 \\
\hline
\end{tabular}

Table 2: Distribution of procedures: conventional method vs harmonic knife $(n=60)$.

\begin{tabular}{|llllll|}
\hline \multirow{2}{*}{ Procedure } & No. & \multicolumn{2}{c|}{ Emergency } & \multicolumn{2}{c|}{ Elective } \\
\hline $\begin{array}{l}\text { Conventional } \\
\text { method }\end{array}$ & 30 & 5 & 16.6 & 25 & 83.33 \\
\hline $\begin{array}{l}\text { Harmonic } \\
\text { Knife }\end{array}$ & 30 & 5 & 16.6 & 25 & 83.33 \\
\hline
\end{tabular}

Table 3: NSI in the surgical team in conventional method and harmonic knife group.

\begin{tabular}{|c|c|c|c|c|}
\hline NSI & $\begin{array}{l}\text { Operations } \\
\text { CM/HK * No. }\end{array}$ & $\begin{array}{l}\text { Exposure to Surgeon } \\
\text { No. }\end{array}$ & $\begin{array}{l}\text { Exposure to first } \\
\text { Assistant No. }\end{array}$ & $\begin{array}{l}\text { Exposure to second assistant } \\
\text { No. }(\%)\end{array}$ \\
\hline \multirow{2}{*}{40} & CM $\quad 30$ & $19(63.3 \%)$ & $4(13.3 \%)$ & 0 \\
\hline & HK & $10(33.3 \%)$ & $7(23.3 \%)$ & 0 \\
\hline
\end{tabular}

* CM: Conventional method, * HK: Harmonic knife

Table 4: Areas of NSI in surgical team in conventional method and harmonic knife group.

\begin{tabular}{|c|c|c|c|c|c|}
\hline \multirow{2}{*}{ Area $(n=40)$} & \multirow{2}{*}{\multicolumn{2}{|c|}{ NSI CM/HK * No. }} & \multicolumn{3}{|l|}{ Exposures } \\
\hline & & & Surgeon No. & First assistant No. & Second assistant No. \\
\hline \multirow{2}{*}{$\begin{array}{l}\text { Dominant hand } \\
\text { NSI } 14(\%)\end{array}$} & $\mathrm{CM}$ & 8 & 7 & 1 & 0 \\
\hline & HK & 6 & 3 & 3 & 0 \\
\hline \multirow{2}{*}{$\begin{array}{l}\text { Non-dominant } \\
\text { hand NSI } 26(\%)\end{array}$} & $\mathrm{CM}$ & 15 & 12 & 3 & 0 \\
\hline & $\mathrm{HK}$ & 11 & 7 & 4 & 0 \\
\hline
\end{tabular}

*CM: Conventional Method, * HK: Harmonic knife

In present study, elective procedures were more common than emergency procedures in both groups (HK and CM).

Table 2 shows distribution of procedures by conventional method and by harmonic knife. $83.3 \%$ patients in each group had elective surgery and $16.6 \%$ had emergency surgery. Elective procedures were more common. Table 3 shows NSI in the surgical team in conventional method and harmonic knife group. Surgeon had NSI in $63.3 \%$ in conventional method and $33.3 \%$ in harmonic knife group. First assistant had NSI in $13.3 \%$ in conventional method, and $23.3 \%$ in harmonic knife group. There were no 
injuries in second assistant. In CM group incidence of NSI among surgeons $(63.3 \%)$ was more than HK group $(33.3 \%)$.

As shown in Table 4, injuries were more in the nondominant hand in both the groups in the surgeon as well as the first assistant. Table 5 and Table 6 show the site of injury in dominant hand and non-dominant hand. Higher number of injuries was noted on index finger in either of the groups.

Predominant age group of source subjects undergoing major surgeries with conventional method and harmonic knife group was 41-50 years. Non dominant hand is more common site for NSI in both conventional and HK group than dominant hand.

Table 5: Sites of NSI in surgical team in conventional method and harmonic knife group (Palmar surface, dominant hand).

\begin{tabular}{|c|c|c|c|c|}
\hline \multirow{2}{*}{ Sites } & \multirow{2}{*}{ CM/HK* } & \multicolumn{3}{|l|}{ NSI } \\
\hline & & Surgeon & First assistant & Second assistant \\
\hline \multirow{2}{*}{ Thumb } & $\mathrm{CM} \quad 1$ & 1 & 0 & 0 \\
\hline & HK 1 & 1 & 0 & 0 \\
\hline \multirow{2}{*}{ Index finger } & CM 5 & 4 & 1 & 0 \\
\hline & HK 3 & 1 & 2 & 0 \\
\hline \multirow{2}{*}{ Middle finger } & CM 1 & 1 & 0 & 0 \\
\hline & HK 1 & 1 & 0 & 0 \\
\hline \multirow{2}{*}{ Ring and little finger } & $\mathrm{CM} \quad 0$ & 0 & 0 & 0 \\
\hline & HK 0 & 0 & 0 & 0 \\
\hline \multirow{2}{*}{ Palm } & $\mathrm{CM} \quad 1$ & 1 & 0 & 0 \\
\hline & HK 1 & 0 & 1 & 0 \\
\hline \multirow{2}{*}{ Total } & CM 8 & 7 & 1 & $\mathbf{0}$ \\
\hline & HK 6 & 3 & 3 & $\mathbf{0}$ \\
\hline
\end{tabular}

* CM: Conventional Method, * HK: Harmonic knife

Table 6: Sites of NSI in surgical team in conventional method and harmonic knife groups (Palmar surface, non-dominant hand)

\begin{tabular}{|c|c|c|c|c|}
\hline \multirow{2}{*}{ Sites } & \multirow{2}{*}{ СM/HK } & \multicolumn{3}{|l|}{ NSI } \\
\hline & & Surgeon & First assistant & Second assistant \\
\hline \multirow{2}{*}{ Thumb } & $\mathrm{CM} \quad 1$ & 1 & 0 & 0 \\
\hline & HK 1 & 0 & 1 & 0 \\
\hline \multirow{2}{*}{ Index finger } & $\mathrm{CM} \quad 7$ & 5 & 2 & 0 \\
\hline & HK 5 & 3 & 2 & 0 \\
\hline \multirow{2}{*}{ Middle finger } & CM 2 & 2 & 0 & 0 \\
\hline & HK 1 & 1 & 0 & 0 \\
\hline \multirow{2}{*}{ Ring and little finger } & CM 0 & 0 & 0 & 0 \\
\hline & HK 0 & 0 & 0 & 0 \\
\hline \multirow{2}{*}{ Palm } & CM 4 & 3 & 1 & 0 \\
\hline & HK 3 & 2 & 1 & 0 \\
\hline \multirow{2}{*}{ Total } & CM 14 & 11 & 3 & $\mathbf{0}$ \\
\hline & HK 10 & 6 & 4 & $\mathbf{0}$ \\
\hline
\end{tabular}

* CM: Conventional Method, * HK: Harmonic knife

\section{DISCUSSION}

In the present study 60 major surgical cases were studied who were divided into 2 groups with 30 patients in each group. Group A consisted of surgery performed by conventional method and Group B consisted of surgery performed by harmonic knife for major gynaecological procedures and general surgical procedures. In today's scenario while operating surgeon and their assistants are exposed to infected or potentially infected blood and body fluids. In spite of all precautions, inadvertently NSI may occur. Since most of NSI occur while operating in depth or while taking suture to control bleeding; harmonic knife cuts and coagulates simultaneously which reduces the bleeding and need for taking surgical suture reduces. 
In the present study that included 60 procedures with needle stick injury, 83.33 percent were elective procedures and 16.67 percent were emergency procedures. Abdominal procedures were 22 and vaginal procedures were 8 in each group. In abdominal procedures, NSI per procedure in surgeon was 0.59 in group A, whereas it was 0.32 in group B. On the other hand, in vaginal procedures, NSI per procedure in surgeon was 0.88 in group $\mathrm{A}$, whereas it was 0.38 in group B. First assistant, mostly a surgery resident suffered NSI in $13.3 \%$ in conventional surgery and $23.3 \%$ with harmonic scalpel in our study. Walee JF in their study on sharp injuries among surgeons observed that surgeons are at risk for injury in the operating room daily. ${ }^{16}$ On average, surgeons report a rate of approximately 11 injuries over a 3-year time period. Unfortunately, medical students and surgery residents are the most vulnerable. Over half the residents reported that they had suffered a needle stick injury, with an average number of 7 injuries during residency. Over half of surgery residents reported that they had suffered a highrisk exposure from injuries, and trainees report feeling rushed, inexperienced and fatigued as contributing factors to their injuries.

NSI were significantly higher in vaginal surgeries than abdominal surgeries due to operative difficulties and limited exposure. Although the causes of needle stick injuries vary widely, multiple studies demonstrate that both fatigue and inexperience play critical roles. Waljee JF stated that $23 \%$ of injuries were attributed to long working hours and sleep deprivation. Injuries are more likely to occur during evening or night shifts when most of the emergency procedures are performed. ${ }^{16}$

Rizk C observed that the most common cause of NSI in the surgical setting most commonly occurs to the surgeon while the suture is being used. ${ }^{17} 90 \%$ injuries were deemed to be "self-inflicted," the majority due to "awkward position," or a "sense of being rushed." However, notable injuries also occur during passage of needle driver and in between suture use. Various safety measures proposed are- utilize the safety blade scalpel blades, no touch technique when assembling and disassembling scalpel blades, avoid placing hands in direction of applied force. The study also suggests that NSI were significantly less with the use of harmonic scalpel as compared to conventional surgery, hence recommend its use judiciously.

Difficult surgeries that included malignancies had higher rate of NSI in the study. Longer duration of surgery, awkward positions and difficult suturing are possible causative factors. Manjunath AP in a study of 29 laprotomies for gynaecological cancers observed glove perforations observed that perforation rate was $13 \%$ per glove. ${ }^{18}$

The perforation was 3 times higher when the duration of surgery was more than 5 hours. The perforation was $63 \%$ for primary surgeons, $54.5 \%$ for first assistant, $4.7 \%$ for $2^{\text {nd }}$ assistant and $40.5 \%$ for scrub nurses. Clinical fellows were at highest risk of injury (94\%). Two third perforations were on index finger or thumb. The glove on non-dominant hand had perforation in $54 \%$ of cases. In $50 \%$ cases participants were not aware of perforations. There were lesser inner glove perforations in double glove compared to single gloves $(\mathrm{p}=0.0004)$

Yang $\mathrm{L}$ in a review on reducing needle stick injuries in healthcare professional observed using new devices to reduce needle stick injuries in healthcare occupations was mainly defined by comparing the number of glove perforations or numbers of needle stick injuries from the study populations with those of control populations. ${ }^{19}$ It was concluded that the current evidence suggests that both safeguard interventions and educational training programs are effective in reducing the risk of having needle stick injuries. However, there are insufficient studies using a combination of both safeguards and educational interventions in both randomized controlled trials and in studies utilizing other designs are needed.

Makaray MA in their study on needle stick injuries among 741 surgeons in training observed that $83 \%$ had needle stick injury during training. ${ }^{20}$ The total number of such injuries during training was 3.8. 67\% reported that the injury was self-inflicted, $81 \%$ reported injury by a solid needle, $72 \%$ reported that injury occurred in the operating room and 52\% reported that it occurred during suturing. A feeling of being "rushed" was identified by $57 \%$. Ninety percent identifies a single cause for the injury. It was suggested that system-based strategies such as the use of "sharpless" methods for handoff and passing of instruments and needles, a safe zone in the operative field, and innovative surgical techniques such as "sharpless surgery" (using nonsharp alternatives whenever possible) and the use of blunt tip needles are associated with a reduced risk of injury.

Ganczak et al in a comparative study of sharp injuries reported by doctors versus nurses from surgical wards in the context of the prevalence of $\mathrm{HBV}, \mathrm{HCV}$ and HIV infections. It was observed that 82 and doctors and $44.4 \%$ nurses $(\mathrm{p} \leq 0.001)$ had sustained at least one sharp injury $12.3 \%$ doctors versus $2.2 \%$ nurses $(\mathrm{p} \leq 0.003)$ sustained more than 10 injuries. The nultivariate regression model revealed that being doctor was associated with greater odds (OR 4.2) of being injured with sharps. Sixty nine percent of nurses sustained a hollow bore needle injury vs $8.9 \%$ doctors $\mathrm{p}<0.001$. Anti $\mathrm{HBC}$ were found in $16.4 \%$ of doctors and $11.2 \%$ of nurses, $\mathrm{p} \geq 0.28$ anti HCV in $1.1 \%$ of doctors versus $1.4 \%$ of nurses, $\mathrm{p}>0.79$ no antiHIV positive cases were found.

Elseviers MM et al in a review of sharp injuries amongst healthcare workers reported that incidence of sharps injuries ranges from 1.4 to 9.5 per $\mathrm{HCW}$, resulting in a weighted mean of $3.7 / 100 \mathrm{HCW}$ per year. ${ }^{22}$ Sharp injuries were associated with infective disease transmissions from 
patients to HCWs resulting in $0.43 \mathrm{HBV}$ infections, .05$1.3 \mathrm{HCV}$ infections and $0.04-0.32 \mathrm{HIV}$ infections per 100 sharps injuries per year. The related societal costs had a mean of 272 pound, amounting to a mean of 1,966 pound if the source patient was HIV positive with HBV and HCV co-infections. They concluded that sharp injuries remain a frequent threat amongst $\mathrm{HCW}$. The follow-up and treatment of sharps injuries and deriving consequences represent a significant cost factor.

Limitations of this study were use of harmonic knife have lower incidence of NSI in group B (P value 0.028 ) which was statistically significant, larger studies with adequate power are needed. Being a delicate and costly instrument adequate number of patients could not be enrolled. Further surgeons need expertise to use it effectively.

\section{CONCLUSION}

It is concluded that NSI are common in surgeons and first assistant. Such injuries are more in non-dominant hand and in procedures where there is little exposure like vaginal hysterectomy. Suture needle is the commonest source of such injury. Use of double glove may be protective to some extent. Use of innovative technologies like harmonic scalpel may be useful. However larger studies are needed.

\section{REFERENCES}

1. Worthigton MG, Ross JJ, Bergeron EK. Posttraumatic stress disorder after occupational HIV exposure: two cases and a literature review. Infect Control Hosp Epidemiol. 2006;27:215-7.

2. Siddique K, Mirja S, Tauqir SF, Anwar I, Malik AZ. Knowledge attitude and practices regarding needle stick injuries amongst healthcare providers. Pakistan J Surg. 2008;24(4):243-8.

3. Veeken H, Verbeek J, Houweling H, Cobelens F. Occupational HIV infection and health care workers in the tropics. Trop Doct. 1991;21(1):28-31.

4. Marcus R. Surveillance of health care workers exposed to blood from patients infected with human immunodeficiency virus. N Engl J Med. 1988;319:111823.

5. Shapiro CN. Occupational risk of infection with hepatitis B and hepatitis C virus. Surg Clin North Am. 1995;75:104756.

6. Bennett B, Duff P. The effect of double gloving on frequency of glove perforations. Obstet Gynecol. 1991;78:1019-22.

7. Maffuli N, Capasso G, Testa V. Glove perforation in elective orthopedic surgery. Acta Orthop Scand. 1989;60:565-6.
8. Panlilio AL, Orelien JG, Srivastava PU, Jagger J, Cohn RD, Carco DM. The NaSH Surveillance Group (CDC). The EPINet data sharing network. estimate of the annual number of percutaneous injuries among hospital-based healthcare workers in the United States, 1997-1998. Infect Control Hosp Epidemiol. 2004;25:556-62.

9. Jagger J, Berguer R, Phillips EK, Parker G, Gomma AE. Increase in sharps injuries in surgical settings versus nonsurgical settings after passage of national needle stick legislation. J Am Coll Surg. 2010;210:496-502.

10. Litta P, Fantinato S, Calonaci F, Cosmi E, Fillippesch M, Zerbetto I, et al. A randomized controlled study comapring harmonic vversus electrosurgery in laparoscopic myomectomy. Fertil Steril. 2010;94(5):1882-6

11. Konno R, Akahira J, Igarshi T, Yamakawa H, Satto S, Yajima A. Conization of cervix using harmonic scalpel. Tohoku J Exp Med. 1999;189:171-8.

12. Lee SJ, Pak KH. Ultrasonic Energy in Endoscopic Surgery. Yonsei Med J. 1999;40(6):545-9.

13. Rele M, Mathur M, Turbadkar D. Risk of needle stick injuries in health care workers - A report. Indian J Med Microbiol. 2002;20:206-7.

14. Jagger J, Bentley M, Tereskerz P. A study of patterns and prevention of blood exposure in or personnel. Aorn J. 1998;67:979-81.

15. Kermode M, Jolley D, Langkham B, Thomas MS, Holmes W, Gifford SM. Compliance with universal/standard precautions among health care workers in rural north India. Am J Infect Control. 2005;33(1):27-33.

16. Walee JF, Malay S, Chung KC. Sharp injuries: the risks and relevance to plastic surgeons. Plast Reconstr Surg. 2013;131(4):784-91

17. Rizk C, Monroe H, Oregno IDA, Rosen T. Needlestick and sharp injuries in dermatologic surgery: a review of preventive techniques and post-exposure protocols. J Clin Aesthet Dermatol. 2016;9(10):41-9.

18. Manjunath AP, Shepherd JH, Barton DPJ, Bridges JE, Ind TEJ. Glove perforations during open surgery for gynaecological malignancies. BJOG. 2008;115:1015-9.

19. Yang L, Mullan B. Reducing needle stick injuries in healthcare occupations: an integerative review of literature. IRSN Nursing. 2011;315432:1-11.

20. Makaray MA, Attar A, Holzmueller CG, Sexton B, Syin D, Gilson MM, et al. Needlestick injuries among surgeons in training. N Engl J Med. 2007;356:2693-9.

21. Ganczak M, Bohatyrewicz A, Korzen M, Karakiewicz B. The comparison of sharp injuries reported by doctors versus nurses from surgical wards in the context of the prevalence of HBV, HCV and HIV infections. Pol Przegl Chir. 2011;284(4):190-5.

22. Elseviers MM, Guillen AM, Gorke A, Arens HJ. Sharp injuries amongst health care workers: reiew of incidence, transmissions and costs. J Ren Care. 2014;40(3):150-6.

Cite this article as: Chadha A, Verma A, Sapna. A study on patterns of needle - stick injuries among gynaecologic and general surgeons in open surgery. Int J Reprod Contracept Obstet Gynecol 2019;8:4852-7. 